\title{
A Method to Improve the Up-Conversion Fluorescence of Polymer Modified $\mathrm{NaYF}_{4}: \mathrm{Yb}, \mathrm{Er}(\mathrm{Tm})$ Nanocomposites
}

\author{
Weina Cui ${ }^{1}$, Siyu $\mathrm{Ni}^{1}$, Shunan Shan ${ }^{2}$, Xingping $\mathrm{Zhou}^{{ }^{*}}$ \\ ${ }^{1}$ College of Chemistry, Chemical Engineering and Biotechnology, Donghua University, Shanghai, China \\ ${ }^{2}$ College of Life and Environment, Shanghai Normal University, Shanghai, China \\ Email: *xpzhou@dhu.edu.cn
}

Received October 3, 2011; revised November 11, 2011; accepted December 15, 2011

\begin{abstract}
The modification of $\mathrm{NaYF}_{4}: \mathrm{Yb}, \operatorname{Er}(\mathrm{Tm})$ nanoparticles synthesized in the presence of an ionic surfactant is critical to their application in biological fields for better solubility and biocompatibility. In this work, $\mathrm{NaYF}_{4}: \mathrm{Yb}, \operatorname{Er}(\mathrm{Tm})$ was transformed from insoluble, inactive to hydrophilic, biocompatible via ligand exchange modification with polyacrylic acid (PAA). Ligand exchange was carried out at room temperature when a colloidal solution of $\mathrm{NaYF}_{4}: \mathrm{Yb}, \operatorname{Er}(\mathrm{Tm})$ in tetrahydrofuran (THF) was treated with excess PAA. The PAA modified $\mathrm{NaYF}_{4}: \mathrm{Yb}, \mathrm{Er}(\mathrm{Tm})$ nanoparticles got better surface properties but with declined inner up-conversion fluorescence. Generally, coating an analogous layer of material outside the core nanoparticles can improve the optical properties of the core. Accordingly, $\mathrm{NaYF}_{4}: \mathrm{Yb}, \mathrm{Er}(\mathrm{Tm}) / \mathrm{NaYF}_{4}$ nanoparticles were synthesized before PAA modification to avoid the optical intensity decaying. The result of fluorescence test proved that the water soluble $\mathrm{NaYF}_{4}: \mathrm{Yb}, \mathrm{Er}(\mathrm{Tm}) / \mathrm{NaYF}_{4} / \mathrm{PAA}$ nanocomposites had a sound up-conversion property compared with that of $\mathrm{NaYF}_{4}: \mathrm{Yb}, \mathrm{Er}(\mathrm{Tm}) / \mathrm{PAA}$. Furthermore, the up-conversion fluorescence property of the nanocomposite varied with the doping ratio of $\operatorname{Er}(\mathrm{Tm})$ to $\mathrm{Yb}$ and the possible mechanism for this change was also discussed.
\end{abstract}

Keywords: Doping Ratio; Fluorescence; Ligand Exchange; Polyacrylic Acid; Sodium Yttrium Fluoride; Surface Modification

\section{Introduction}

Up-conversion fluorescence materials are attracting much attention, owing to their unique optical properties and potential applications. Among all the up-conversion fluorescence materials, hexagonal-phase $\mathrm{NaYF}_{4}: \mathrm{Yb}, \operatorname{Er}(\mathrm{Tm})$ is one of the most efficient $980 \mathrm{~nm}$ near-infrared (NIR) to visible (green and blue) up-conversion phosphors $[1,2]$. In bulk, the low phonon energy of the host strongly suppresses multiphonon relaxation process in the emission centers, leading to up-conversion emission. $\mathrm{Yb}^{3+}$ working as a activator with $\mathrm{Y}^{3+}$ sensitizes $\mathrm{Er}^{3+}\left(\mathrm{Tm}^{3+}\right)$ to emit green (blue) and red lights. In the recent decade, the research of up-conversion materials was mainly focused on the biological and medical fields such as low-intensity IR imaging and sensitive bioprobes [3,4].

Biological application of the up-conversion fluorescence materials presents new challenges of the development of nano-sciecnce and nano-technology, especially the surface modification study of nanoparticles. As well known, ligand exchange is a versatile way to modify the surfaces of nanoparticles for better solubility and bio-

"Corresponding author. compatibility. Dykstra et al. [5] prepared the CdSe/ZnS nanoparticles by an organometallic route in the presence of trioctylphosphine oxide (TOPO) and then used (PEG)phosphine oxide copolymer to remove the TOPO for obtaining hydrophilic nanoparticles. Zhang et al. [6] chose polyacrylic acid and poly-allylamine to replace the originnal hydrophobic ligand on magnetic nanoparticles at an elevated temperature in a glycol solvent and rendered it high water solubility. Lin et al. [7] successfully synthesized at $150^{\circ} \mathrm{C}$ the OA-capped $\mathrm{PbS}$ QDs with emission in the NIR and modified the PbS by ligand exhange with polyelectrolytes for the application of deep-tissue in vivo imaging.

Ligand exchange is also suitable for the modification of $\mathrm{NaYF}_{4}$. In our work, PAA was chosen as the ligand polymer because of its excellent properties including hydrophilicity, abundant reactant groups (carboxyl) and non-toxicity. In order to eliminate the quenching effect from polymer, the nanoparticles of $\mathrm{NaYF}_{4}: \mathrm{Yb}, \mathrm{Er}(\mathrm{Tm}) / \mathrm{NaYF}_{4}$ core-shell were firstly synthesized before PAA modification [8]. The middle $\mathrm{NaYF}_{4}$ layer protected the inner core and its crystal structure, thus enhancing the fluorescence property. The final resultant of $\mathrm{NaYF}_{4}: \mathrm{Yb}, \mathrm{Er}(\mathrm{Tm}) / \mathrm{NaYF}_{4} / \mathrm{PAA}$ nanocomposites prom- 
ised to have better comprehensive properties, which made it possible to be applied in biological fields.

To the best of our knowledge, fluorescence properties of the $\mathrm{NaYF}_{4}$ with a size of several nanometers after modification are barely discussed, although the research about the up-converting fluorescence of $\mathrm{NaYF}_{4}$ core material has been widely carried out. However, in our work, fluorescence properties of the $\mathrm{NaYF}_{4}: \mathrm{Yb}, \mathrm{Er}(\mathrm{Tm}) / \mathrm{PAA}$ core-shell nanoparticles and the $\mathrm{NaYF}_{4}: \mathrm{Yb}, \mathrm{Er}(\mathrm{Tm}) / \mathrm{NaYF}_{4} /$ PAA core-shell-shell nanocomposites were mainly explored. It is more significant to study the fluorescence of polymer modified $\mathrm{NaYF}_{4}$, as the existence of polymer often causes the quenching effect which is one of the most important influence factors for a bio-labeling material. Besides that, the color changing rules of $\mathrm{NaYF}_{4}: \mathrm{Yb}$, $\mathrm{Er}(\mathrm{Tm}) / \mathrm{NaYF}_{4} / \mathrm{PAA}$ nanocomposites were also revealed in this article. It is the first time to explore the relationship in details between lanthanide doping ratio and fluorescence property of the nanoparticles after modificatioin with PAA.

\section{Experimental}

\subsection{Synthesis of the Host Material: Hexagonal $\mathrm{NaYF}_{4}$ Nanoparticles}

The synthesis basically followed the routes below. Briefly, the yttrium perchlorate $\left(\mathrm{Y}\left(\mathrm{ClO}_{4}\right)_{3}\right)$ was prepared at the beginning by dissolving the rare earth oxide in perchlorate acid. Ten $\mathrm{mL}$ of $0.4 \mathrm{M} \mathrm{Y}\left(\mathrm{ClO}_{4}\right)_{3}$ was dispersed in 60 $\mathrm{mL}$ cyclohexane. Under vigorous stirring in a three-neck flask, the mixture was heated to $40^{\circ} \mathrm{C}$ and maintained for $20 \mathrm{~min}$ after the addition of some amount of the surfacetant sodium oleate of $0.4 \mathrm{M}$. Then, $20 \mathrm{~mL}$ of $0.8 \mathrm{M}$ sodium fluoride was added into this reaction system and maintained at the same temperature for $60 \mathrm{~min}$. The final mixture was standing for $15 \mathrm{~min}$ to gain an obvious interface between oil and water phases. The product was dispersed homogeneously in $60 \mathrm{~mL}$ of cyclohexane (oil layer). $\mathrm{NaYF}_{4}$ nanoparticles were precipitated by centrifugation and ultrasonication treatments for the cyclohexane solution and washed by ethanol and hydroxide sodium for at least 3 times.

\subsection{Synthesis of $\mathrm{NaYF}_{4}: \mathrm{Yb}, \mathrm{Er}(\mathrm{Tm})$ Nanoparticles and $\mathrm{NaYF}_{4}: \mathrm{Yb}, \operatorname{Er}(\mathrm{Tm}) /$ $\mathrm{NaYF}_{4}$ Core/Shell Nanoparticles}

The synthesis of $\mathrm{NaYF}_{4}: \mathrm{Yb}, \operatorname{Er}(\mathrm{Tm})$ is similar to that of $\mathrm{NaYF}_{4}$ nanoparticles. The lanthanides were put into the reaction system in the form of rare earth perchlorate including $\mathrm{Y}\left(\mathrm{ClO}_{4}\right)_{3}, \mathrm{Yb}\left(\mathrm{ClO}_{4}\right)_{3}, \mathrm{Er}\left(\mathrm{ClO}_{4}\right)_{3}$ and $\mathrm{Tm}\left(\mathrm{ClO}_{4}\right)_{3}$. Ten $\mathrm{mL}$ mixture of a designated molar ratio of $\mathrm{Y}$ to $\mathrm{Ln}$ $\left(0.4 \mathrm{M} \mathrm{Y}\left(\mathrm{ClO}_{4}\right)_{3}\right.$ and $\mathrm{Ln}\left(\mathrm{ClO}_{4}\right)_{3}(\mathrm{Ln}=\mathrm{Yb}, \operatorname{Er}(\mathrm{Tm}))$ was dispersed in $60 \mathrm{~mL}$ cyclohexane. The reaction condition and other procedures are the same as those of $\mathrm{NaYF}_{4}$ mentioned above. $\mathrm{NaYF}_{4}: \mathrm{Yb}, \operatorname{Er}(\mathrm{Tm})$ nanoparticles were precipitated by centrifugating half of the cyclohexane (oil layer) suspension.

Recently, several similar methods have been reported in the literature for synthesizing $\mathrm{NaYF}_{4}: \mathrm{Yb}, \mathrm{Er}(\mathrm{Tm}) /$ $\mathrm{NaYF}_{4}$ core/shell nanoparticles [9-11]. In this paper, we also take this way to produce $\mathrm{NaYF}_{4}: \mathrm{Yb}, \operatorname{Er}(\mathrm{Tm}) / \mathrm{NaYF}_{4}$ core/shell nanoparticles. In a typical process, five $\mathrm{mL} 0.4$ $\mathrm{M} \mathrm{Y}\left(\mathrm{ClO}_{4}\right)_{3}$ and $5 \mathrm{~mL}$ of sodium oleate solution $(0.4 \mathrm{M})$ were then put into another half of the cyclohexane suspension and stirred for $20 \mathrm{~min}$. Ten $\mathrm{mL}$ of $0.8 \mathrm{M}$ sodium fluoride was added and vigorously stirred for $60 \mathrm{~min}$. All the reactions were carried out at $40^{\circ} \mathrm{C}$. After centrifugation, the resulting nanoparticles of $\mathrm{NaYF}_{4}: \mathrm{Yb}, \operatorname{Er}(\mathrm{Tm})$ and $\mathrm{NaYF}_{4}: \mathrm{Yb}, \mathrm{Er}(\mathrm{Tm}) / \mathrm{NaYF}_{4}$ core/shell composites were dried in vacuum at $60^{\circ} \mathrm{C}$ for at least $12 \mathrm{~h}$.

\subsection{PAA Surface Modification of $\mathrm{NaYF}_{4}$ : $\mathrm{Yb}, \mathrm{Er}$ (Tm) and $\mathrm{NaYF}_{4}: \mathrm{Yb}, \mathrm{Er}(\mathrm{Tm}) / \mathrm{NaYF}_{4}$ Core/Shell Nanoparticles via Ligand Exchange}

The $\mathrm{NaYF}_{4}: \mathrm{Yb}, \operatorname{Er}(\mathrm{Tm}) / \mathrm{PAA}$ and $\mathrm{NaYF}_{4}: \mathrm{Yb}, \operatorname{Er}(\mathrm{Tm}) /$ $\mathrm{NaYF}_{4} / \mathrm{PAA}$ were prepared by mixing a solution of excess PAA with that of $\mathrm{NaYF}_{4}$ nanoparticles in tetrahydrofuran (THF) and then stirred overnight. Herein, THF is good solvent for hydrophilic PAA and hydrophobic $\mathrm{NaYF}_{4}$ nanoparticles, and the other organic solvents don't reach the same effects as THF does. Taking the synthesis of $\mathrm{NaYF}_{4}: \mathrm{Yb}, \mathrm{Er} / \mathrm{PAA}$ as an example, PAA $(84.7 \mathrm{mg})$ was mixed with $\mathrm{NaYF}_{4}: \mathrm{Yb}, \operatorname{Er}(20.8 \mathrm{mg})$ in $\operatorname{THF}(15.0 \mathrm{~mL})$ in a $50 \mathrm{~mL}$ conical flask and this mixture was stirred at $30^{\circ} \mathrm{C}$ overnight. The resultant was homogeneous and ivory white in color. This conical flask was then placed into a boiling water bath to evaporate the THF. After the solvent evaporation, a white solid was obtained. This white solid was then washed by sodium hydroxide and alcohol for 3 times. $\mathrm{NaYF}_{4}$ : $\mathrm{Yb}, \mathrm{Er} / \mathrm{PAA}$ was not soluble in cyclohexane but can readily be transferred to methanol or water to form robust colloidal solutions.

\subsection{Characterization}

TEM images of the $\mathrm{NaYF}_{4}: \mathrm{Yb}, \operatorname{Er}(\mathrm{Tm})$ nanoparticles and $\mathrm{NaYF}_{4}: \mathrm{Yb}, \mathrm{Er}(\mathrm{Tm}) / \mathrm{NaYF}_{4}$ core/shell nanocom-posites were collected on a JEOL JEM 3010 transmission electron microscope. Powder X-ray diffraction spectra were acquired with a D8 advance X-ray diffractometer, with $\mathrm{Cu} \mathrm{K} \alpha$ radiation at $1.5406 \AA$ Á. Fourier transform infrared spectroscopy (FTIR) was performed to further characterize the composition and structure of the nanocomposites. Samples of the modified nanoparticles were ground with $\mathrm{KBr}$ and then compressed into slices. The spectrum was taken from 500 to $3500 \mathrm{~cm}^{-1}$. 


\subsection{Fluorescence Property}

Up-conversion fluorescence spectra were obtained on a LS-55 luminescence spectrometer (Perkin-Elmer) with an external $980 \mathrm{~nm}$ laser diode (1 W, continuous wave with $1 \mathrm{~m}$ fiber, Beijing Viasho Technology Co.) as the excitation source in place of the Xe-lamp in the spectrometer. For comparison, all the nanoparticles were milled to powder and compressed into the groove.

\section{Results and Discussion}

\subsection{Size Analysis of the Core Nanoparticles by XRD and TEM}

Figure 1 shows the X-ray diffraction (XRD) result of the host material $\mathrm{NaYF}_{4}$. The well-defined peaks indicated the high crystallinity of the nanoparticles. The peak positions and intensities of XRD patterns matched closely with those of hexagonal $\beta-\mathrm{NaYF}_{4}$ in JCPDF $(28$ - 1192) [9]. From the line breadth of the diffraction peaks, the crystallite size of the samples was estimated to be approximately $6.9 \mathrm{~nm}$ for $\mathrm{NaYF}_{4}$ nanoparticles based on the Debye-Scherrer formula.

Figures 2(a) and (b) show the transmission electron microscopy (TEM) images of $\mathrm{NaYF}_{4}: \mathrm{Yb}, \mathrm{Er}(\mathrm{Tm})$ core and $\mathrm{NaYF}_{4}: \mathrm{Yb}, \mathrm{Er}(\mathrm{Tm}) / \mathrm{NaYF}_{4}$ core/shell nanoparticles, respectively. It was calculated that the average sizes of them were $8.2 \mathrm{~nm}$ and $12.0 \mathrm{~nm}$, respectively. The doping ratio of Lanthanide $\mathrm{Yb}, \mathrm{Er}(\mathrm{Tm})$ is so tiny compared with yttrium that Figure 2(a) also can represent the TEM image of $\mathrm{NaYF}_{4}$ host materials. So the size of $\mathrm{NaYF}_{4}(8.2 \mathrm{~nm})$ from TEM is basically consistent with the result $(6.9 \mathrm{~nm})$ from Debye-Scherrer formula.

\subsection{FTIR Spectra of $\mathrm{NaYF}_{4}: \mathrm{Yb}, \mathrm{Er}(\mathrm{Tm})$ Nanoparticles before and after PAA Modification}

To demonstrate the capping of PAA on the nanoparticles, FTIR spectra of the $\mathrm{NaYF}_{4}: \mathrm{Yb}, \mathrm{Er}(\mathrm{Tm}) / \mathrm{PAA}$ (Figure 3(c)) were compared with those of $\mathrm{NaYF}_{4}: \mathrm{Yb}, \mathrm{Er}(\mathrm{Tm})$ without surface modification (Figure 3(a)) and pure PAA (Figure 3(b)). In Figure 3(a), the intense bands in the vicinity of $2920 \mathrm{~cm}^{-1}$ and $2850 \mathrm{~cm}^{-1}$ are due to the antisymmetric and symmetric vibration of the $-\mathrm{CH}_{2}$, and the bands in $1545 \mathrm{~cm}^{-1}$ and $1457 \mathrm{~cm}^{-1}$ are contributed to $\mathrm{C}=\mathrm{O}$ antisymmetric and symmetric stretching vibrations of carboxylate groups. The band position and shape are the same as the FTIR spectra of sodium oleate [12], so it is concluded that the nanoparticles are capped with sodium oleate before modification. It is obvious that the nanoparticles after ligand exchange (Figure 3(c)) have no absorption band of $-\mathrm{CH}_{2}$ and two new bands appear near $1600 \mathrm{~cm}^{-1}$ and $1400 \mathrm{~cm}^{-1}$ corresponding to the R-COO antisymmetric and symmetric stretching vibrations. The

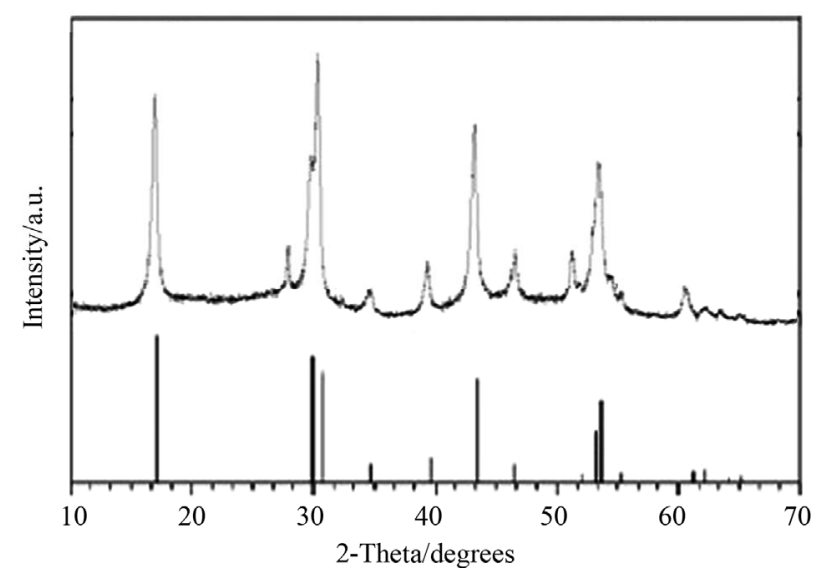

Figure 1. XRD pattern of $\mathrm{NaYF}_{4}$ nanocrystals synthesized with sodium oleate.

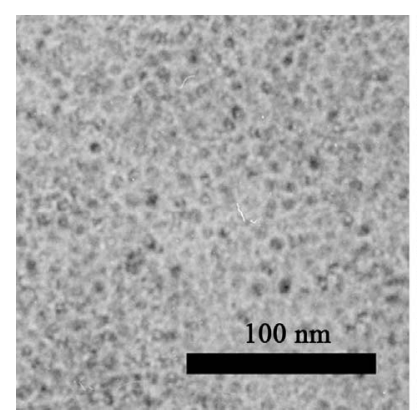

(a)

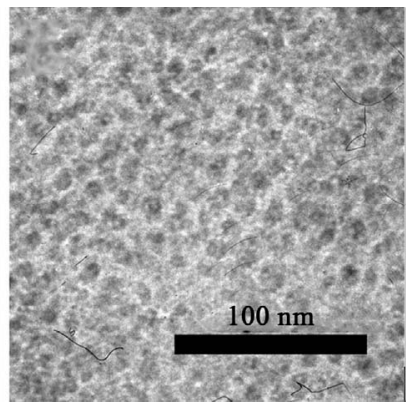

(b)
Figure 2. TEM images of (a) $\mathrm{NaYF}_{4}: \mathrm{Yb}, \operatorname{Er}(\mathrm{Tm})$ and (b) $\mathrm{NaYF}_{4}: \mathrm{Yb}, \mathbf{E r}(\mathrm{Tm}) / \mathrm{NaYF}_{4}$.

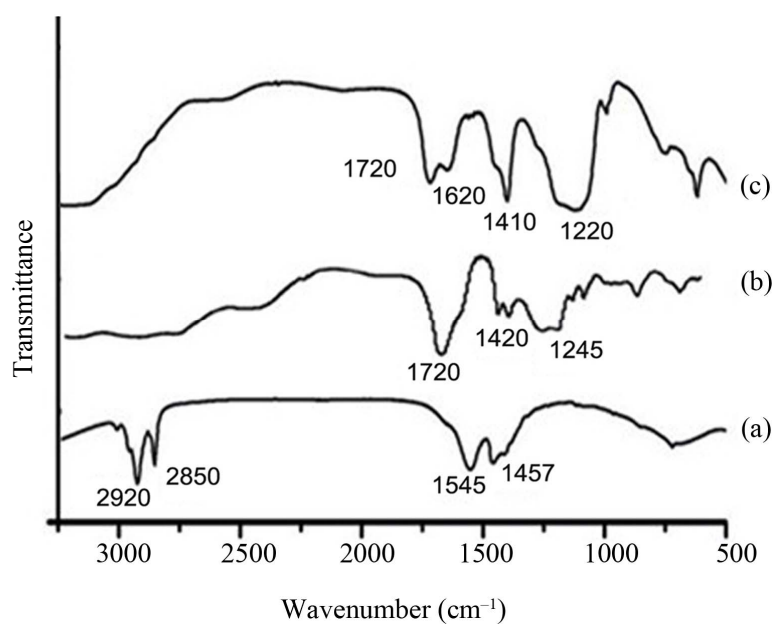

Figure 3. FTIR spectra of (a) $\mathrm{NaYF}_{4}: \mathrm{Yb}, \mathrm{Er}(\mathrm{Tm})$; (b) Pure PAA; and (c) $\mathrm{NaYF}_{4}$ :Yb,Er(Tm)/PAA.

appearance of $\mathrm{R}-\mathrm{COO}^{-}$stretching vibration can also be found in the other nanocomposites, such as polyacrylic acid modified aluminum oxide and ferroferric oxide $[13,14]$. This observation clearly indicates that the sodium oleate on the surface of nanoparticles has been successfully replaced by PAA. 


\subsection{Fluorescence Properties of $\mathrm{NaYF}_{4}: \mathrm{Yb}, \mathrm{Er}$ (Tm), NaYF 4 : $\mathrm{Yb}, \mathrm{Er}(\mathrm{Tm}) / \mathrm{PAA}$, and $\mathrm{NaYF}_{4}$ : $\mathrm{Yb}, \mathrm{Er}(\mathrm{Tm}) / \mathrm{NaYF}_{4} / \mathrm{PAA}$}

Figure 4 shows the up-conversion luminescence mechanism of $\mathrm{NaYF}_{4}: \mathrm{Yb}, \mathrm{Er}(\mathrm{Tm})$. Up-conversion is an effective avenue for the generation of visible emission with near-infrared (NIR) excitation, which is based on sequential photon absorption and energy transfer steps [15].

In the case of $\mathrm{NaYF}_{4}: \mathrm{Yb}, \mathrm{Er}$, under the excitation of $980 \mathrm{~nm}$ light, which can be absorbed by $\mathrm{Yb}^{3+}$, the electrons of $\mathrm{Er}^{3+}$ are first excited from the ${ }^{4} \mathrm{I}_{15 / 2}$ to higher level via excitation energy transfer from $\mathrm{Yb}^{3+}$ to $\mathrm{Er}^{3+}$ and then to the ${ }^{4} \mathrm{~F}_{7 / 2}$ level by absorbing the energy of another electron from $\mathrm{Yb}^{3+}\left({ }^{2} \mathrm{~F}_{5 / 2}\right)$. The excited electrons of the ${ }^{4} \mathrm{~F}_{7 / 2}\left(\mathrm{Er}^{3+}\right)$ level then decay to the emitting ${ }^{2} \mathrm{H}_{11 / 2}$ (the line at $540 \mathrm{~nm}$ ), and ${ }^{4} \mathrm{~F}_{9 / 2}$ levels (the line at $650 \mathrm{~nm}$ ), mainly through nonradioactive process. Meanwhile, as for $\mathrm{NaYF}_{4}$ : $\mathrm{Yb}, \mathrm{Tm}$, the emission process is a little different. $\mathrm{An} \mathrm{Yb}^{3+}$ ion in the ${ }^{2} \mathrm{~F}_{7 / 2}$ ground state absorbs a $980 \mathrm{~nm}$ photon and transits to excited state ${ }^{2} \mathrm{~F}_{5 / 2}$. When it drops back to the ground state $\left({ }^{2} \mathrm{~F}_{5 / 2}-{ }^{2} \mathrm{~F}_{7 / 2}\right)$, energy is transferred to an adjacent ground state $\left({ }^{3} \mathrm{H}_{6}\right) \mathrm{Tm}^{3+}$ ion. After the multistep excitation energy transfer, the $\mathrm{Tm}^{3+}$ is promoted to the ${ }^{1} \mathrm{D}_{2}$ and ${ }^{1} \mathrm{G}_{4}$ emission levels. These excited electrons on the emitting levels $\left({ }^{1} \mathrm{D}_{2}\right.$ and $\left.{ }^{1} \mathrm{G}_{4}\right)$ then drop back to the low-energy levels $\left({ }^{3} \mathrm{~F}_{4}\right.$ and $\left.{ }^{3} \mathrm{H}_{6}\right)$ via fluorescence emission $[16,17]$. But the ${ }^{1} \mathrm{D}_{2}$ level of $\mathrm{Tm}^{3+}$ commonly cannot be populated by the photon from $\mathrm{Yb}^{3+}$ via energy transfer to the ${ }^{1} \mathrm{G}_{4}$ due to the large energy mismatch between them [18].

Figures 5 and $\mathbf{6}$ show the up-conversion fluorescence spectra of $\mathrm{NaYF}_{4}: \mathrm{Yb} 10 \%$, Er (Tm) 3\% before and after surface modification with a $0-1500 \mathrm{mw}$ adjustable 980 $\mathrm{nm}$ laser. In Figure 5, the straight line represents the $\mathrm{NaYF}_{4}: \mathrm{Yb}, \mathrm{Er}$ core material, where the green emission around $540 \mathrm{~nm}$ and the red emission around $650 \mathrm{~nm}$ are attributed to the transitions of ${ }^{2} \mathrm{H}_{11 / 2}{ }^{4} \mathrm{I}_{15 / 2}$ and ${ }^{4} \mathrm{~F}_{9 / 2}{ }^{4} \mathrm{I}_{15 / 2}$ for the $\mathrm{Er}^{3+}$ ions. It is obvious that the emission band of dash line representing $\mathrm{NaYF}_{4}$ : $\mathrm{Yb}, \mathrm{Er} / \mathrm{PAA}$ is very weak due to the quenching effect from organic PAA. Nevertheless, the emission intensity of $\mathrm{NaYF}_{4}: \mathrm{Yb}, \mathrm{Er} / \mathrm{NaYF}_{4} / \mathrm{PAA}$ showed as the dot dash line is dramatically increased by the protection of middle $\mathrm{NaYF}_{4}$ layer. Especially the red emission band at $650 \mathrm{~nm}$ is almost as high as that of the $\mathrm{NaYF}_{4}: \mathrm{Yb}$,Er nanoparticles before modification.

In the case of $\mathrm{NaYF}_{4}: \mathrm{Yb}, \mathrm{Tm}$ (shown in Figure 6), the red emission appears at the same position and the blue emission is shifted to $470 \mathrm{~nm}$ arising from the ${ }^{1} \mathrm{G}_{4}$ to ${ }^{3} \mathrm{H}_{6}$ energy transition. Likewise, the emission intensity of $\mathrm{NaYF}_{4}: \mathrm{Yb}, \mathrm{Tm} / \mathrm{NaYF}_{4} / \mathrm{PAA}$ is higher than that of $\mathrm{NaYF}_{4}$ : $\mathrm{Yb}, \mathrm{Tm} / \mathrm{PAA}$. So it is concluded that the middle $\mathrm{NaYF}_{4}$ layer works as a protecting layer which can reduce the influence on fluorescent intensity probably caused from the organic modification.

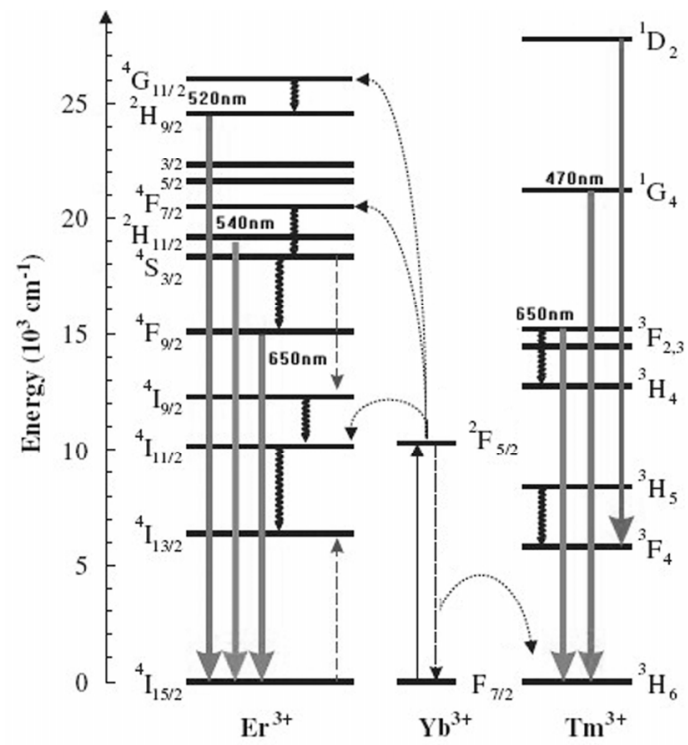

Figure 4. Schematic energy level diagrams: upconversion excitation and visible emission schemes for the $\mathrm{Er}^{3+}, \mathbf{T m}^{3+}$ and $\mathrm{Yb}^{3+}$ ions.

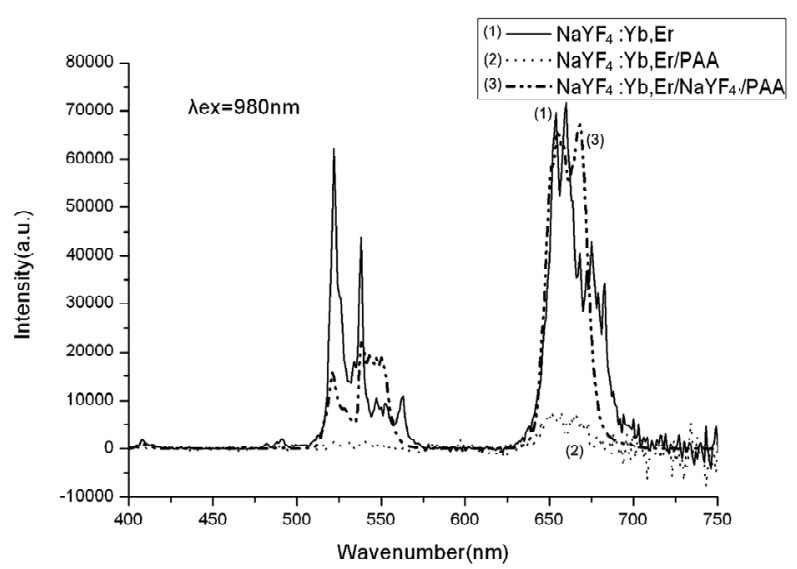

Figure 5. Fluorescent spectra of nanoparticles doped with $\mathbf{Y b}^{3+}, \mathbf{E r}^{3+}$ before and after PAA modification.

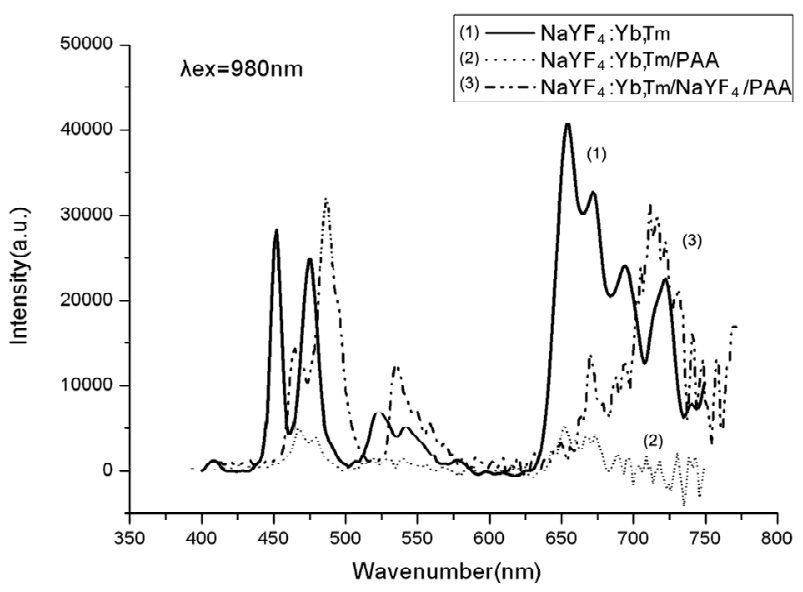

Figure 6. Fluorescent spectra of nanoparticles doped with $\mathrm{Yb}^{3+}, \mathrm{Tm}^{3+}$ before and after PAA modification. 


\subsection{Influence of $\mathrm{Yb} / \mathrm{Er}(\mathrm{Tm})$ Doping Ratio on the Up-Conversion Property}

Figures 7 and $\mathbf{8}$ show the up-conversion fluorescence spectra of $\mathrm{NaYF}_{4}: \mathrm{Yb}, \mathrm{Er} / \mathrm{NaYF}_{4} / \mathrm{PAA}$ and $\mathrm{NaYF}_{4}: \mathrm{Yb}$, $\mathrm{Tm} / \mathrm{NaYF}_{4} / \mathrm{PAA}$ under $980 \mathrm{~nm}$ excitation, respectively. It is clear that all samples show strong emissions in the visible region. Upon addition of more $\mathrm{Er}^{3+}$ to $\mathrm{Yb}^{3+}$, there is a marked increase in the emission ratio of red to green, as can be seen by comparison among Figures 7(a)-(c). This effect is probably related to the increased possibility of the two-ion $\mathrm{Er}^{3+}$ cross-relaxation process $\left({ }^{4} \mathrm{I}_{15 / 2},{ }^{4} \mathrm{~S}_{3 / 2^{-}}\right.$ ${ }^{4} \mathrm{I}_{13 / 2},{ }^{4} \mathrm{I}_{9 / 2}$ ) that occurs at higher $\mathrm{Er}^{3+}$ concentrations. This process depopulates the green-emitting ${ }^{4} \mathrm{~S}_{3 / 2}$ state, thereby increasing the red to green ratio [19]. But in the case of $\mathrm{NaYF}_{4}: \mathrm{Yb}, \mathrm{Tm} / \mathrm{NaYF}_{4} / \mathrm{PAA}$, the result is just contrary (Figures 8(a)-(c)). With the increase of $\mathrm{Tm}^{3+}$ to $\mathrm{Yb}^{3+}$ ratio, the red to blue emission is reduced. It shows that at higher $\mathrm{Tm}^{3+}$ concentration, the $\mathrm{Tm}^{3+}$ cross-relaxation process of ${ }^{3} \mathrm{~F}_{2},{ }^{3} \mathrm{H}_{4}{ }^{3} \mathrm{H}_{5},{ }^{1} \mathrm{G}_{4}$ increases, which plays an important role in populating ${ }^{1} \mathrm{G}_{4}$ Level, thus enhancing the blue emission [17]. It is very significant to find out the color changing rules versus lanthanide doping ratio for fulfilling the different practical requirements. For example, in the fields of in vivo imaging and labeling, the variety of color emission can provide more than one binding site to image several bi-molecules at the same time. The fluorescence property is the key for the material to be successfully applied and then further arduous work should be done in the future.

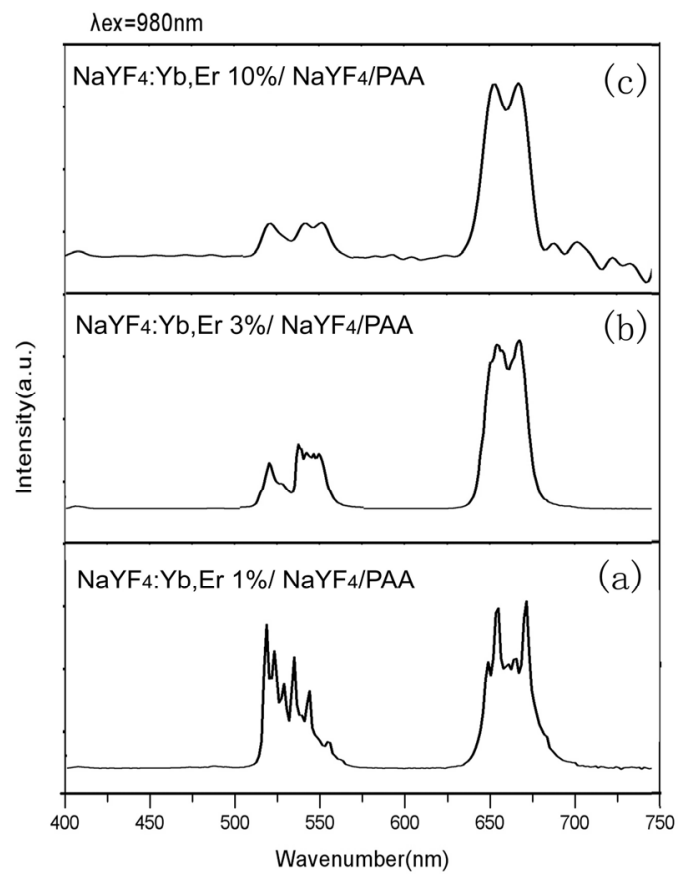

Figure 7. Fluorescent spectra of $\mathrm{NaYF}_{4}: \mathrm{Yb}, \mathrm{Er} / \mathrm{NaYF}_{4} / \mathrm{PAA}$ of different $\mathrm{Er}^{3+}$ doping ratios: (a) $1.0 \% \mathrm{Er}^{3+}$; (b) $3.0 \% \mathrm{Er}^{3+}$; (c) $10.0 \% \mathrm{Er}^{3+}$.

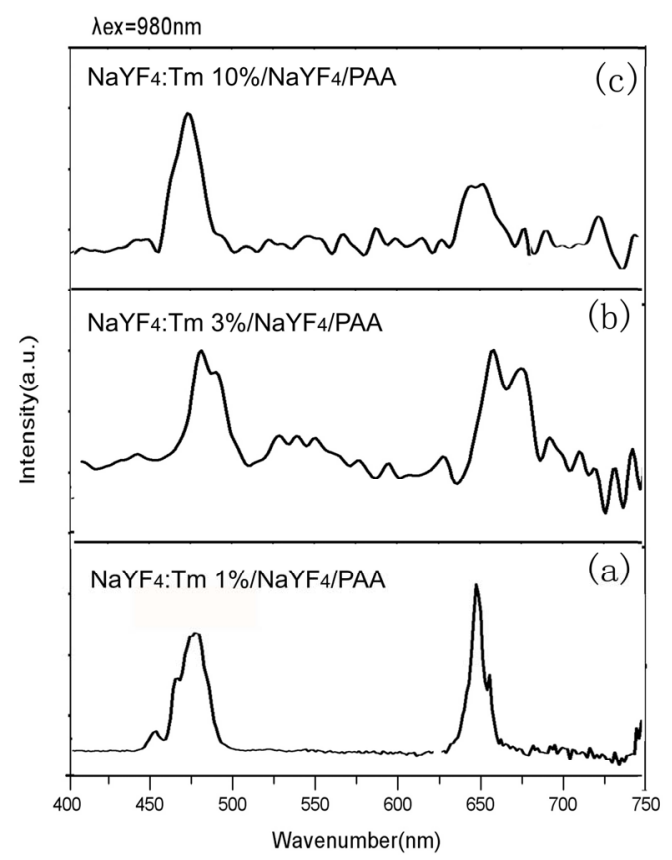

Figure 8. Fluorescent spectra of $\mathrm{NaYF}_{4}: \mathrm{Yb}, \mathrm{Tm} / \mathrm{NaYF}_{4} / \mathrm{PAA}$ of different $\mathrm{Tm}^{3+}$ doping ratio: (a) $1.0 \% \mathrm{Tm}^{3+}$; (b) $3.0 \%$ $\mathrm{Tm}^{3+}$; (c) $10.0 \% \mathrm{Tm}^{3+}$.

\section{Conclusion}

Polymer modification of $\mathrm{NaYF}_{4}: \mathrm{Yb}, \mathrm{Er}(\mathrm{Tm})$ can improve the surface property of nanoparticles but decrease the fluorescent intensity of the inner material because of quenching effect. In this study, we described a method to alleviate the quenching effect by coating another $\mathrm{NaYF}_{4}$ layer outside $\mathrm{NaYF}_{4}: \mathrm{Yb}, \mathrm{Er}(\mathrm{Tm})$ inner core to resist the influence from PAA (polyacrylic acid). Photoluminescence checking showed that the up-converting fluorescent intensity of $\mathrm{NaYF}_{4}: \mathrm{Yb}, \mathrm{Er}(\mathrm{Tm}) / \mathrm{NaYF}_{4} / \mathrm{PAA}$ was obviously higher than that of $\mathrm{NaYF}_{4}: \mathrm{Yb}, \mathrm{Er}(\mathrm{Tm}) / \mathrm{PAA}$, thus proving the efficiency of this method. Another focus of this paper here was mainly on the relationship between the specific red/green (blue) emission value and $\mathrm{Yb} / \mathrm{Er}$ (Tm) doping ratio. In summary, when doping the $\mathrm{Yb}$ and Er ions, the higher $\mathrm{Er}^{3+}$ concentrations increased the red to green emission ratio. In contrary, the higher $\mathrm{Tm}^{3+}$ cencentrations just weaken the red emission but enhanced the blue one. The controllable fluorescence efficiency and hydrophilicity with desirable carboxylic functional groups provided by PAA give the core/shell/shell nanocomposites a great potential to be bio-probes.

\section{Acknowledgements}

The authors thank Shanghai Municipal Natural Science Foundation (Grant 10ZR1400600), Shanghai Municipal 2010 Nanometer Special Project (Grant 1052nm06400), and the Fundamental Research Funds for the Central Universities for their financial supports. 


\section{REFERENCES}

[1] N. Menyuk, K. Dwight and J. W. Pierce, "NaYF 4 :Yb, Er-An Efficient Upconversion Phosphor," Applied Physics Letters, Vol. 21, No. 4, 1972, pp. 159-163. doi:10.1063/1.1654325

[2] G. S. Yi and G. M. Chow, "Synthesis of Hexagonal- Phase $\mathrm{NaYF}_{4}: \mathrm{Yb}, \mathrm{Er}$ and $\mathrm{NaYF}_{4}: \mathrm{Yb}, \mathrm{Tm}$ Nanocrystals with Efficient Up-Conversion Fluorescence," Advanced Functional Materials, Vol. 16, No. 18, 2006, pp. 2324-2329. doi:10.1002/adfm.200600053

[3] F. van de Rijke, H. Zijlmans, S. Li, T. Vail, A. K. Raap, R. S. Niedbala and H. J. Tanke, "Up-Converting Phosphor Reporters for Nucleic Acid Microarrays," Nature Biotechnology, Vol. 19, 2001, pp. 273-276. doi: $10.1038 / 85734$

[4] G. S. Yi, H. C. Lu, S. Y. Zhao, G. Yue, W. J. Yang, D. P. Chen and L. H. Guo, "Synthesis, Characterization and Biological Application of Size-Controlled Nanocrystalline $\mathrm{NaYF}_{4}: \mathrm{Yb}$,Er Infrared-to-Visible Up-Conversion Phosphors," Nano Letters, Vol. 4, No. 11, 2004, pp. 2191- 2196. doi:10.1021/n1048680h

[5] S. W. Kim, S. Kim, J. B. Tracy, A. Jasanoff and M. G. Bawendi, "Phosphine Oxide Polymer for Water-Soluble Nanoparticles," Journal of the American Chemical Society, Vol. 127, No. 13, 2005, pp. 4556-4557. doi:10.1021/ja043577f

[6] T. R. Zhang, J. P. Ge, Y. X. Hu and Y. D. Yin, “A General Approach for Transferring Hydrophobic Nanocrystals into Water," Nano Letters, Vol. 7, No. 10, 2007, pp. 3203-3207. doi:10.1021/n1071928t

[7] W. J. Lin, F. Karolina, G. Gerald, R. B. Ghasem, H. Sean, S. Vlad, H. S. Edward, D. S. Gregory and A. W. Mitchell, "Highly Luminescent Lead Sulfide Nanocrystals in Organic Solvents and Water through Ligand Exchange with Poly (Acrylic Acid)," Langmuir, Vol. 24, No. 15, 2008, pp. 8215-8219. doi:10.1021/la800568k

[8] X. P. Zhou, S. S. Li, X. L. Chen, Q. Zhu, Z. Q. Wang and J. Zhang, "Formation of Nanocrystalline Matrix of Sodium Rare Earth Fluoride Up-Conversion Phosphors," Journal of Nanoscience and Nanotechnology, Vol. 8, No. 10, 2008, pp. 1392-1397.

[9] G. S. Yi and G. M. Chow, "Water-Soluble $\mathrm{NaYF}_{4}$ :Yb, $\mathrm{Er}(\mathrm{Tm}) / \mathrm{NaYF}_{4} /$ Polymer Core/Shell/Shell Nanoparticles with Significant Enhancement of Upconversion Fluorescence," Chemistry of Materials, Vol. 19, No. 3, 2007, pp. 341- 343. doi:10.1021/cm062447y

[10] H. S. Qian and Y. Zhang, "Synthesis of Hexagonal-Phase Core-Shell $\mathrm{NaYF}_{4}$ Nanocrystals with Tunable Upconversion Fluorescence," Langmuir, Vol. 24, No. 21, 2008, pp.
12123-12125. doi:10.1021/la802343f

[11] H. X. Hai, Y. W. Zhang, L. D. Sun and C. H. Yan, "Highly Efficient Multicolor Up-Conversion Emissions and Their Mechanisms of Monodisperse $\mathrm{NaYF}_{4}$ : $\mathrm{Yb}, \mathrm{Er}$ Core and Core/Shell-Structured Nanocrystals," The Journal of Physical Chemistry C, Vol. 111, No. 37, 2007, pp. 1372113729. doi: $10.1021 / \mathrm{jp} 073920 \mathrm{~d}$

[12] S. Perviz, "Effect of Sodium Oleate on the Agglomeration of Calcium Carbonate," Crystal Research and Technology, Vol. 40, No. 3, 2005, pp. 226-232. doi: $10.1002 /$ crat.200410330

[13] K. Vermöhlen, H. Lewandowski, H. D. Narres and E. Koglin, "Adsorption of Polyacrylic Acid on Aluminium Oxide: DRIFT Spectroscopy and Ab Initio Calculations," Colloids and Surfaces A: Physicochemical and Engineering Aspects, Vol. 170, No. 2-3, 2000, pp. 181-189. doi:10.1016/S0927-7757(00)00408-8

[14] S. S. Wei, Y. Zhang and J. R. Xu, "The Dynamic Rheology Behaviors of Reactive Polyacrylic Acid/Nano- $\mathrm{Fe}_{3} \mathrm{O}_{4}$ Ethanol Suspension," Colloids and Surfaces A: Physicochemical and Engineering Aspects, Vol. 296, No. 1-3, 2007, pp. 51-56. doi:10.1016/j.colsurfa.2006.09.021

[15] L. Y. Wang and Y. D. Li, "Controlled Synthesis and Luminescence of Lanthanide Doped $\mathrm{NaYF}_{4}$ Nanocrystals," Chemistry of Materials, Vol. 19, No. 4, 2007, pp. 727734. doi:10.1021/cm061887m

[16] G. F. Wang, W. P. Qin, J. S. Zhang, L. L. Wang, G. D. Wei, P. F. Zhu and K. Ryongjin, "Controlled Synthesis and Luminescence Properties from Cubic to Hexagonal $\mathrm{NaYF}_{4}: \mathrm{Ln}^{3+}(\mathrm{Ln}=\mathrm{Eu}$ and $\mathrm{Yb} / \mathrm{Tm})$ Microcrystals," Journal of Alloys and Compounds, Vol. 475, No. 1-2, 2009, pp. 452-455. doi:10.1016/j.jallcom.2008.07.050

[17] X. Chen, W. J. Wang, X. Y. Chen, J. H. Bi, L. Wu, Z. H. $\mathrm{Li}$ and $\mathrm{X}$. Z. Fu, "Microwave Hydrothermal Synthesis and Upconversion Properties of $\mathrm{NaYF}_{4}: \mathrm{Yb}^{3+}, \mathrm{Tm}^{3+}$ with Microtube Morphology," Materials Letters, Vol. 63, No. 12, 2009, pp. 1023-1026. doi:10.1016/j.matlet.2009.01.075

[18] C. H. Liu, H. Wang, X. Li and D. P. Chen, "Monodisperse, Size-Tunable and Highly Efficient $\beta$-NaYF $4: \mathrm{Yb}, \operatorname{Er}(\mathrm{Tm})$ Up-Conversion Luminescent Nanospheres: Controllable Synthesis and Their Surface Modifications," Journal of Materials Chemistry, Vol. 19, No. 21, 2009, pp. 3546-3553. doi: $10.1039 / \mathrm{b} 820254 \mathrm{k}$

[19] J. F. Suyver, J. Grimm, M. K. van Veen, D. Biner, K. W. Kramer and H. U. Güdel, "Upconversion Spectroscopy and Properties of $\mathrm{NaYF}_{4}$ Doped with $\mathrm{Er}^{3+}, \mathrm{Tm}^{3+}$ and/or $\mathrm{Yb}^{3+}$," Journal of Luminescence, Vol. 117, No. 1, 2006, pp. 1-12. doi:10.1016/j.jlumin.2005.03.011 